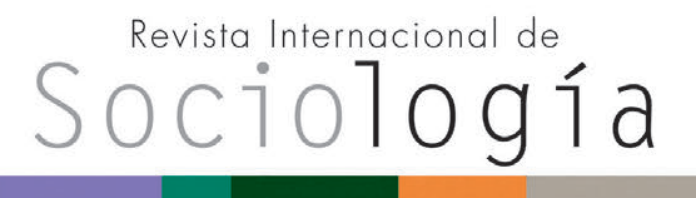

Revista Internacional de Sociología RIS

vol. 75 (1), e051, enero-marzo, 2017, ISSN-L:0034-9712

doi: http://dx.doi.org/10.3989/ris.2017.75.1.15.127

\section{EL PAPEL DE LA NATURALEZA FÍSICA Y BIOLÓGICA EN LA SOCIOLOGÍA DE NORBERT ELIAS Entre el naturalismo y el sociologismo}

Jesús Romero MoñIVAs

Universidad Complutense de Madrid, España

Jesus.romero@edu.ucm.es

ORCID iD: http://orcid.org/0000-0003-4673-4977

Cómo citar este artículo / Citation: Romero Moñivas, J. 2017. "El papel de la naturaleza física y biológica en la sociología de Norbert Elias. Entre el naturalismo y el sociologismo". Revista Internacional de Sociología 75 (1): e051. doi: http://dx.doi.org/10.3989/ris.2017.75.1.15.127

\section{Resumen}

Este artículo tiene como objetivo desarrollar aquellos aspectos de la obra de Norbert Elias en los que entran en juego consideraciones acerca de la naturaleza físico-cosmológica y la naturaleza biológica en su comprensión de la sociedad y del ser humano. Su interés en las ciencias físico-naturales se descubre en gran parte de su producción escrita, especialmente en sus trabajos dedicados a la emergencia cosmológica de los diferentes niveles de la realidad y en lo que respecta a las discusiones acerca de la naturaleza humana. Puede concluirse que el papel de la naturaleza en Elias es ambivalente y bascula entre el naturalismo y el sociologismo, con puntos de contacto y colisión con ambos.

\section{Palabras Clave}

Biología y sociología; Coevolución genes-cultura; Interdisciplinariedad; Naturaleza humana.

\section{THE ROLE OF PHYSICAL AND BIOLOGICAL NATURE IN THE SOCIOLOGY OF NORBERT ELIAS Between naturalism and sociologism}

Copyright: (C) 2017 CSIC. Este es un artículo de acceso abierto distribuido bajo los términos de la licencia Creative Commons Attribution (CC BY) España 3.0.

Recibido: 24/08/2015. Aceptado: 03/06/2016. Publicado on line: 02/03/2017

\section{Abstract}

This article aims to develop the aspects of Norbert Elias's work which deals on the physical-cosmological nature and biological nature for his understanding of society and human beings. His interest in the physical and natural sciences is found in much of his writing, especially those dedicated to the cosmological emergence of different levels of reality and those deals on discussions about human nature. That the role of nature in Elias is ambivalent and it swings between naturalism and sociologism, with points of contact and collision with both, can be concluded.

\section{KEYWORDS}

Biology and Sociology; Gen-culture Coevolution; Human Nature; Interdisciplinarity. 


\section{INTRODUCCIÓN}

Norbert Elias (1897-1990) siempre mantuvo interés en las ciencias físico-naturales y en la constitución biológica del ser humano, como lo pone de manifiesto el hecho de que llevara a sus clases de sociología una maqueta del cerebro humano, porque pensaba que la estructura neuronal-biológica era esencial para comprender la sociedad (1984: $41,106)$. En otro trabajo anterior (Romero Moñivas 2013a) traté de poner de manifiesto que su sociología de la libertad podía ser apta para un diálogo con las neurociencias, por la importancia que concedía al carácter biológico del ser humano, especialmente a su arquitectura cerebral, algo normalmente ausente en las explicaciones más culturalistas dentro de la sociología. En este artículo, expongo algunos de sus fundamentos teóricos que tienen una relación más directa con el papel de la naturaleza física y biológica, especialmente sobre ontología, antropología, gnoseología y epistemología, y que muestran puntos de conexión o colisión con otras propuestas sociales más propiamente "naturalistas", es decir, aquellas que de modo explícito han introducido la naturaleza biológica del ser humano en sus explicaciones. El primer epígrafe rastrea las consideraciones eliasianas sobre la naturaleza física y sus consecuencias ontológicas, en el segundo intento establecer los elementos esenciales de lo que Elias entiende por naturaleza humana, finalmente dos epígrafes más breves tratan de su defensa del dinamismo macroevolutivo y de su concepción epistemológica de tipo interdisciplinar.

\section{QuÉ NATURALEZA FísICA Y QUÉ CONSECUENCIAS ONTOLÓGICAS}

\section{La gran evolución cosmológica}

El debate más onmicomprehensivo y que, bajo su paraguas, alberga otras cuestiones más concretas a las que volveré más adelante, es una temática generalmente ausente en la sociología: el problema ontológico general de la constitución de la realidad. Esta problemática es metateórica (Wilterdkink 2012: 4 ), es decir, es una cuestión de fondo que, sin embargo, afecta directamente a las teorías de rango medio, pero también a la metodología preferida y a la epistemología defendida por cada sociólogo. Sin embargo, el problema al que se enfrenta Elias no es meramente el de la ontología social (Outhwaite 2006), sino que se retrotrae a la constitución de la realidad como un todo; es un problema cosmológico.

El rasgo característico del pensamiento eliasiano desde su juventud (1921: 26) es el rechazo del dualismo en todos los niveles ontológicos: natural, social y humano (cf. Kilminster 2007: 132; Dunning 1986: 286, nota 25). Elias concibe la realidad como un progresivo surgimiento de niveles de integración irreductibles unos a otros, semejante a lo que actualmente se conoce como "monismo o materialismo emergentista" o "monismo de aspecto dual", que es la ontología seguramente dominante en la teoría de sistemas complejos, ciencia cognitiva y filosofía de la mente ${ }^{1}$. Su punto de partida es materialista: no acepta una dualidad de principios ontológicos, sino que parte del proceso cósmico evolutivo desde un Big Bang físico, cuya complejidad cosmológica interpretará a la manera en que lo hacía el relacionalismo y organicismo en filosofía de la ciencia y en la biología teórica en la primera mitad del siglo XX (cf. Quilley 2010). El gran macroproceso de constitución de la realidad es lo que Elias Ilama "la gran evolución" ('die Große Evolution'), que comienza con el Big Bang. A partir de esta explosión inicial surgirán el resto de niveles de realidad: físico-químico, biológico, humano y social, que exigirán la aparición de diversas ciencias. Estos niveles tienen grados diversos de integración, complejización y diferenciación funcional, son dependientes de los niveles anteriores pero no reductibles a ellos, y son producto de dos tipos de síntesis que explican la diferencia de integración: síntesis "reversibles" y "no reversibles".

En las primeras, los elementos constituyentes que se integran en un nivel superior no están unidos de modo funcional, por ello "la síntesis puede revertirse $\sin$ que estas unidades constituyentes pierdan sus propiedades". En las segundas, el nivel de integración es mayor, puesto que los elementos constituyentes están unidos funcionalmente, y "en este caso las partes pierden su estructura propia cuando la unidad de orden superior, es decir, la síntesis que las reúne, se rompe" (1983b: 196). Un ejemplo del primer tipo es la molécula simple y del segundo los organismos unicelulares. Por lo tanto, para Elias la gran evolución es "un proceso evolutivo espontáneo, no planeado, pero direccionado, [que] bajo determinadas circunstancias, unidades de integración de estructura reversible $y$, en este sentido, más débil hacen surgir unidades de integración de estructura irreversible formadas por componentes cada vez más especializados y por centros de integración cada vez más elevados dentro de un ordenamiento jerárquico" (1983b: 200). Esta evolución comenzó en el nivel físico-químico y ha continuado hasta el ser humano como la "configuración más compleja", aunque el proceso no parece tener fin, puesto que los seres humanos se han integrado en el nivel de grupos, estados, figuraciones interestatales, etc., que son integraciones irreversibles de niveles cada vez más elevados.

Esa evolución cosmológica ha dado lugar a dos niveles, la vida y la conciencia, tan complejos que para explicarlos se ha recurrido a conceptos metafísicos como "fuerza vital", "alma" o "razón" (1983b: 203). Fiel al monismo emergentista considera que la vida y la conciencia son producto de una reor- 
ganización e integración funcional de elementos de niveles inferiores: es decir, la vida y la conciencia no son sustancias ontológicas metafísicas, sino niveles funcionales distintos. En el proceso evolutivo no hay surgimiento de una "sustancia" nueva, sino un escalón más elevado en el proceso de integración y diferenciación funcional y relacional de las partes constituyentes, es decir, la emergencia de dos ámbitos o áreas funcionales ('Funktionsbereiche'): "hay órganos y funciones que sirven al mantenimiento $y$ a la constante reproducción del organismo mismo, y hay órganos y funciones que sirven a la relación del organismo con otras porciones del mundo y a su autodirección en tales relaciones" (1983: 57). Elias opina que es una "manera demasiado estática y sustancializadora" referirnos a estos dos ámbitos con los términos "cuerpo" y "mente", "alma", "razón", "espíritu” o "conciencia", porque con ello se evoca "más la idea de sustancias que la de funciones, transmiten más la noción de algo que descansa en sí mismo que la noción de algo cambiante. Parecen hacer referencia a algo que es de la misma manera ['gleichen Weise ist da] que el estómago y el cráneo" (1983: 56-57). Sin embargo, considera que "las propuestas de solución puramente físicas y metafísicas son representativas de un mismo y único modo de pensar, e igualmente inadecuadas. Sean monistas o dualistas, atribuyan a la 'mente' cualidades de la 'materia' o a la 'materia' cualidades de la 'mente', todas estas propuestas intentan explicar un todo a partir de sus partes" (1956: 230). Por el contrario, "la organización e integración de las partes ejercen una determinada influencia sobre las propiedades y el comportamiento de las unidades compuestas, $y$, bastante a menudo, también sobre las partes constituyentes" (1982b: 228). Por ello, el fisicalismo no es viable porque desconoce la peculiaridad de las unidades altamente organizadas e integradas que constituyen los niveles superiores. Hay una "causalidad ascendente" de las partes que componen los niveles de integración, y una "causalidad descendente" (pero no supraorgánica o sociologista) que deriva del carácter de la unidad integrada. Esta causalidad descendente tiene capacidad para determinar, puesto que "las propiedades de su configuración, de su interdependencia funcional o, en otras palabras, de la estructura de la unidad compuesta superan con mucho las de sus partes componentes consideradas aisladamente, en cuanto determinantes de las propiedades de la unidad compuesta" (1974: 153).

En definitiva, frente a los materialistas reduccionistas considera que estos nuevos niveles de vida y conciencia son tan "reales" como los elementos fisicoquímicos que ellos estudian. Y frente a los vitalistas metafísicos, este nuevo nivel de "realidad" no implica asumir la existencia de una sustancia inmaterial independiente de la materia, sino que los niveles de integración superiores son "reales" en cuanto a su estructuración funcional. Por supuesto, difícilmente se encontrará en las ciencias humanas una fundamentación ontológica de la realidad físico natural de tendencia dualista-metafísica, con las notables excepciones del neurofisiólogo John Eccles y el neurocientífico Roger W. Sperry, versiones modernas del dualismo sin ser estrictamente cartesianos (Sanguineti 2014: 103-109). En el otro extremo identificado por Elias, se encontraría el caso del materialismo eliminativo de los filósofos de la mente Paul Churchland (1981) y Patricia Churchland (1986).

\section{La ontología social figuracional}

El doble ataque al fisicalismo y a la metafísica respecto a la ontología de la realidad físico-natural tiene su correlato en la ontología social, alejándose del individualismo (considerado reduccionista) y del sociologismo (considerado metafísico), proponiendo en su lugar una ontología centrada en las "figuraciones": "los individuos siempre participan en configuraciones y las configuraciones de individuos son irreductibles" (1965: 170; 1969: 127; Romero Moñivas 2013b: 168176). Lo primero significa que el punto de partida de toda investigación sociológica es "una pluralidad de individuos que en uno u otro modo son interdependientes", y lo segundo que las configuraciones no pueden ser explicadas como si "existieran de algún modo independientemente de los individuos, ni en términos que impliquen que los individuos existen de algún modo independientemente de ellas".

Esta ontología social sitúa a Elias más acá del modelo sociologista de las ciencias sociales, pero también más allá de la estricta exigencia darwinista de pasar de un "pensamiento tipológico" a un "pensamiento poblacional" (Mayr 1982), es decir, que la selección natural no actúa en el nivel de la especie, sino del individuo (y más concretamente en sus genes), lo que en las ciencias sociales más naturalistas conduce a un estricto individualismo. Al contrario que para la ortodoxia naturalista, su ontología figuracional parece encontrarse más cerca de autores que han puesto de manifiesto que es importante no quedar enclaustrado en el "individuo" (ni sus genes); de ahí que se propongan otros mecanismos de selección complementarios, como lo hace la "teoría de la selección multinivel" -minoritaria y muy debatida aun entre los biólogos- propuesta por George Price y defendida por Sober y Wilson, que mantiene la posibilidad de selección en una jerarquía de diferentes niveles (especialmente genes, organismos, grupos): "La selección multinivel implica la posibilidad de que un rasgo sea favorecido a un nivel pero seleccionado en contra en otro, o que diferentes genes que afectan a una característica concreta reciban presiones selectivas contradictorias como consecuencia de que se están transmitiendo en distintos niveles; esto es lo que se conoce con el nombre de conflicto genómico" (Soler 2002: 80). Esta jerarquía multinivel 
rescata -lejos del ingenuo sentido clásico de "por el bien del grupo"- la selección "a nivel de grupo": la selección de grupo implica que un rasgo evolutivo que mejora a los individuos de un grupo, puede ser seleccionado positivamente porque los grupos que tienen a muchos de esos individuos entre su población son grupos que salen beneficiados respecto a otros que no los tienen (Dunbar et al. 2011: 25). Es decir, la selección de grupo prevalece solo si es más fuerte que la selección dentro del grupo. De hecho, la teoría de selección multinivel es una cuarta forma de explicar la aparición del altruismo como mecanismo biológico adaptativo, lo que supone la posibilidad de que un rasgo que puede tener un coste privado para el individuo sea favorecido por la selección natural en el nivel de grupo (Wilson y Wilson 2009). La selección sigue actuando solo sobre el "individuo" (como exige la biología evolutiva), pero un individuo que está inserto dentro de un grupo para el que ese rasgo es beneficioso en la competencia con otros grupos: aunque las migraciones reducen la variación genética entre grupos como para que actúe la selección natural, este mecanismo es especialmente importante en la variación cultural entre grupos.

La ontología figuracional eliasiana se me antoja más cercana a esta última postura. En este sentido, el proceso de civilización actúa sobre los sujetos que se encuentran sometidos a interdependencias competitivo-cooperativas dando lugar a diversos grados de equilibrio entre hetero-controles y auto-controles (Elias 1939). Si un sujeto de una figuración muy estrecha poseyera un rasgo genético heredable (o apareciera una variante cultural) que le hiciera más proclive al auto-control en vez de a la conducta impulsiva, ese rasgo podría ser adaptativo porque facilitaría la vida del grupo, evitando los costes grupales tanto de un sujeto excesivamente impulsivo que disgregaría la vida colectiva como los que se derivan de mantener altos niveles de coacción externa para evitar esos impulsos individuales; aun reconociendo que la selección natural seguiría seleccionando desde el punto de vista de los genes a los sujetos menos cooperadores por sus ventajas individuales. Se produciría así una coevolución genes-cultura entre el proceso de psicogénesis y el de sociogénesis, a través del cual las variantes genéticas o culturales interactúan en diversos niveles determinando en cada caso su éxito o su fracaso.

\section{QuÉ concepto de nATURALEZA HUMANA}

Aunque el término "naturaleza humana" es casi inexistente en la literatura sociológica, Elias suele utilizarlo con cierta asiduidad en muchas de sus obras. El concepto en sí mismo es ambiguo y polimorfo y dependiente de las controversias intra e interdisciplinares (Castro Nogueira et al. 2008). A continuación trataré de entresacar algunos de los elementos de la visión de la naturaleza humana en la obra eliasiana.

\section{La imbricación coevolutiva biológico-cultural}

La primera cuestión a tratar es la más general, la que sitúa la peculiaridad humana como una imbricación compleja de genes y cultura, de lo biológico y lo social. En Elias la imbricación biológico-cultural deriva del proceso cosmológico monista-emergentista. Lo humano y lo social son un nuevo nivel del macroproceso cosmológico que tenemos que interpretar en el mismo sentido que todos los otros niveles: derivado de y anclado en el nivel anterior, pero no reducido a él. Por ello, para Elias "los seres humanos son parte de un orden natural ["Naturordnung'] y de un orden social ['Gesellschaftsordnung]" (1983: 65), puesto que "los procesos biológicos y sociales dependen uno de otro" (1991: 19). El hombre es radicalmente animal-biológico a la vez que profundamente cultural, es un "posanimal"; "los seres humanos, aunque descienden de los animales, 'están equipados por naturaleza con facultades' que solo ellos poseen en la comunidad viva de la tierra" (1991: 43, cursiva mía). Es evolutivamente "un nuevo nivel", cuya peculiaridad no está en sustancias metafísicas espirituales independientes de lo natural. El sociólogo alemán considera que todo el ser humano es natural y es la propia naturaleza la que ha facultado unas propiedades biológicas peculiarmente humanas que necesitan el aprendizaje social y la comunidad de seres humanos para poder desarrollarse. Estas propiedades previas son el fundamento de la condición cambiante del ser humano, ya que por "naturaleza humana" no hay que entender lo invariable, lo que no cambia, sino lo que permite una mayor flexibilidad. En este sentido, el concepto de naturaleza aplicado al ser humano debe ser "re-definido". Esta concepción de la naturaleza humana es poco arriesgada, puesto que parece sentirse más cómoda con una visión "hueca", "flexible" y "maleable" de lo biológico, lejos de las tesis más estrictamente naturalistas de la psicología evolutiva, que consideran la naturaleza humana como un conjunto de dispositivos de contenido preprogramados genéticamente que sesgan nuestras conductas y decisiones. Para Elias, la naturaleza humana parece terminar deshaciéndose en consideraciones sociológicas y de aprendizaje:

\footnotetext{
"Por naturaleza, esto es, debido a la constitución hereditaria ['ererbten Konstitution] del organismo humano, la conducta humana está organizada de tal manera que los impulsos innatos la determinan en menor medida que los impulsos debidos a la experiencia individual y el aprendizaje. No es que los hombres por su constitución biológica puedan ['können'] aprender a dirigir su conducta en mayor medida que otros seres vivos, es que su conducta debe ['muß] ser dirigida por el aprendizaje. Un joven humano no solo puede sino que debe desarrollar en gran medida a través del aprendizaje el esquema de su conducta para poder sobrevivir. Considerada tan solo como dispositivo 'técnico' ['technische Einrichtung'] la dirección de la conducta activada por el
} 
aprendizaje individual [...], es muchísimo más eficiente que la dirección de la conducta [...] por medio de mecanismos hereditarios $y$, en este sentido, ciegos. El dispositivo ampliado del aprendizaje, favorecido por el desarrollo del cerebro, de la musculatura de la garganta y el rostro y de las manos tiene como condición por tanto una reducción, una retirada, por así decirlo, de la dirección ciega, automática e innata de la conducta" (1970: 116).

No creo que Llinás (2003: 156-205) objetara nada a esta cita eliasiana, teniendo en cuenta que la complejidad del cerebro humano permite la coexistencia de un cableado genético de aprendizaje filogenético que desencadena muchos patrones de acción fijos (PAF) estereotipados, pero a la vez biológicamente se produce una necesidad de alterar y modificar esos PAF para permitir un distanciamiento de la acción inmediata y, por tanto, la adaptación y la emergencia de fenómenos complejos como el lenguaje y el pensamiento. La única diferencia es que Elias quizá minimiza en exceso el cableado innato, acercándose más -sin asumirla- a la vieja concepción de la "tabula rasa".

De hecho, si esto es así en un sentido, en otro Elias manifiesta una clara concepción de que lo cultural no puede ser un elemento ad hoc, externo, que se sobreañade apareciendo de la nada, a lo biológico. Al contrario, si se divorcia lo cultural de lo biológico, como a menudo sucede en la sociología más culturalista y constructivista, "la mente, cultura o, en realidad, lenguaje, permanecen en este caso sin estatus ontológico, sin anclaje en el mundo observable. Se dejan [...] colgando en el aire" (ibíd.). Esta preocupación por dejar fenómenos esencialmente humanos sin un anclaje sólido en una previa estructura biológica reaparece en Elias en temáticas tan suyas como el tiempo, el conocimiento, las autocoacciones, etc. (cf. infra). Esa "constitución natural" como condición de posibilidad se aplica prácticamente a todo lo que posteriormente requiere el aprendizaje social. De hecho, Elias se interroga: “¿cómo podrían los seres humanos aprender algo, si ellos no estuviesen equipados por naturaleza, es decir, biológicamente, para ello?" (1987: 110), “¿cuáles son las peculiaridades estructurales del hombre que hacen posible la historia? [...] ¿Qué peculiaridades biológicas son premisas de la variabilidad y particularmente de la capacidad de desarrollo de las sociedades humanas?" (1969: 114). Evidentemente, en Elias esta constitución biológica es muy general, flexible, vaga, muy en consonancia con los enfoques sociológicos poco proclives al naturalismo. Sin embargo, como insistiré, Elias sí reconoce algunos datos biológicos irreductibles a lo social.

Esta dualidad de orden de pertenencia humano (biológico y cultural) alimenta de ambigüedad el problema. Quizá por su formación médica y en las ciencias físico-naturales no puede obviar el carácter biológico del ser humano; pero a la vez su nueva ocupación como sociólogo le impele a poner de manifiesto la vacuidad de lo biológico frente a la poderosa capacidad constructora de lo social. Para intentar hacer justicia a ambas cosas Elias distingue dos tipos de estructuras "naturales": aquellas que no son cambiantes ni siquiera por aprendizaje y aquellas que "permanecen como disposiciones ['dispositions] y no pueden funcionar completamente" a menos que sean estimuladas por el amor y el aprendizaje de otras personas (1987: 110). Es lo que considera como el "entrelazamiento" ('intertwining') de dos procesos: el biológico de "maduración" y el social de "aprendizaje", que mantienen una mutua referencia necesaria, uniendo naturaleza y cultura-sociedad. Este entrelazamiento genéticocultural es esencial para comprender la peculiar flexibilidad humana que es, de hecho, posibilitada por su propia constitución biológica evolutivamente construida. Esta solución de compromiso le permite de alguna forma mantener la ambigüedad sin caer ni en el biologicismo ni en el constructivismo. Con ello puede situar en una previa naturaleza humana todo fenómeno social que, para serlo, necesita emerger de alguna, si acaso remota, disposición de la naturaleza humana, no dejándola "en el aire"; y a la vez su emergentismo le libera de las cadenas de lo biológico para poder desarrollar investigaciones más estrictamente sociológicas descuidando cómo lo biológico actúa en esos niveles más altos.

Esta es una postura habitual de todas las ciencias humanas que pretenden sostenerse en el equilibrio entre los abismos del determinismo biologicista y del constructivismo culturalista, queriendo salvaguardar a la vez ese doble orden social y natural. Lo que diferencia unos enfoques de otros es el grado en que basculan más hacía uno u otro de esos abismos y la desvergüenza teórica con la que lo manifiestan. Por ejemplo, el neurobiólogo Damasio (2010: 26-27) distingue también entre la automatizada e inconsciente "homeostasis básica-biológica" y la creada y guiada reflexivamente "homeostasis socio-cultural". Y Churchland explica el altruismo de una manera semejante, puesto que especialmente para el caso de los mamíferos (y posiblemente las aves sociales) el bienestar de nuestros seres queridos pertenece a nuestra propia "homeostasis interna", porque surgen sentimientos de miedo y ansiedad ante la perspectiva de separación de la descendencia o de amenaza contra ella, así como alivio y placer cuando los padres se unen con su descendencia o el peligro pasa. La homeostasis interna biológica ha evolucionado para incluir el desarrollo del apego social; lo que significa que, como quería Elias, lo sociocultural no es un añadido externo a lo biológico, sino que encuentra acomodo y sentido en la propia estructura biológica evolutiva, que coevoluciona conjuntamente con lo social $y$, aunque relativamente se desarrolla de forma autónoma, no puede disociarse de ella. 
A pesar de la innegable ambigüedad de este doble "orden", Elias ha mantenido la imbricación de ambos a través del concepto de "entrelazamiento", lo que le permitiría estar en consonancia con el principio sólidamente establecido que rechaza la idea de que podamos separar lo que es genético de lo que es socio-cultural, atribuyendo un peso específico de cada uno de ellos en la constitución de los fenómenos socio-humanos (Pinker 2002: 542-550; Greenspan 2004; Flint et al. 2010). Hablar de un estricto determinismo neurológico o genético como explicación de la diversidad cultural es una caricatura ideológica que actualmente no tiene ningún serio defensor en el campo de las ciencias físiconaturales (Castro Nogueira 2013: 108). Una gráfica explicación de la verdadera comprensión conjunta o interaccionista de genes-cultura nos la ofrece Dunbar et al. (2011: 40), al considerar que un pastel es el resultado de cocinarlo con determinados ingredientes (genes) dentro de un horno (ambiente), a lo que yo añadiría: siguiendo una determinada receta (cultura), sin poder separarlos del resultado final. Esta concepción biosocial se expresa en Elias no solo en la coevolución entre la psicogénesis y la sociogénesis del proceso de civilización, también la encontramos en la explicación del genio de Mozart que integra una innombrable disposición genética y una concreta figuración socio-artística (1991b: 68, 85), así como en la explicación de la violencia de los niños a los que el instinto de agresión y alarma del orden natural se añade el orden social de la herencia sociológica paterna (1965: 120; 1970: 199, nota 27; 1939, I: 263-283); pero es especialmente importante en su negación del dualismo gnoseológico entre el sujeto y el mundo, puesto que las capacidades cognitivas humanas han coevolucionado dentro y en contacto con ese supuesto mundo exterior de objetos cognoscibles (1991: 95-98).

Esta coevolución interaccionista no impide, sin embargo, como ya advirtiera Etzioni en los años setenta, que la cultura pueda ser dañina para la naturaleza humana y las personas (Franks 2013: 99), es decir, que en terminología eliasiana: el "desarrollo social" ('Entwicklung') genere pautas de comportamiento que contravengan la "evolución biológica" ('Evolution'). La cultura como elemento adaptativo de la naturaleza humana tiene un ritmo de evolución propio, más rápido normalmente que el biológico, y puede producir elementos culturales concretos maladaptativos desde el punto de vista de su aptitud biológica, especialmente porque el ser humano está más expuesto al aprendizaje e imitación no-parental (Richerson y Boyd 2005), a través de los procesos de emulación y búsqueda de aprobación (Castro Nogueira et al. 2008). Las drogas, las frenéticas carreras profesionales, etc. son ejemplos citados a menudo. Para que funcione esta agresión de lo cultural (del desarrollo) a lo biológico (a la evolución) es necesario reconocer algún tipo de naturaleza huma- na previa a la experiencia social, a la que esta última agrede inconscientemente. Pero, por paradójico que resulte, es igualmente necesario que esa experiencia social sea ella misma producto a la vez de la previa naturaleza humana. Como el Frankestein humanamente creado que se independiza y amenaza a su creador. En el caso de Elias esta paradoja es habitual: el potencial de coacción (cf. infra) que es un atributo biológico previo, permite un progresivo desarrollo histórico-cultural de los autocontroles que termina por eliminar la espontaneidad de los afectos e incluso da lugar a vidas excesivamente rígidas y lánguidas para las que se requiere la introducción de tensiones placenteras a través del ocio y el deporte; es decir, devolviendo a la naturaleza humana su tono emocional necesario (Elias 1986).

\section{La unidad de la naturaleza humana}

Ese doble orden de pertenencia del ser humano implica, a la vez, que existe una unidad de naturaleza humana y una diversidad de concreción sociocultural. El "entrelazamiento" opera como un crisol donde emergen diferencias humanas que, sin embargo, siguen ancladas en la unicidad biológica. Por ello, con sincera perplejidad intelectual, un Elias de 31 años se sorprendía de cómo era posible que unos seres humanos no sean capaces de comprender a otros seres humanos, aun teniendo "todos la misma mente ['desselben Geistes]" (1928: 112). La perplejidad eliasiana ante este hecho deriva de su monismo ontológico: ontológica y biológicamente la humanidad es una: "hay solo un 'hombre' [einen Menschen gibt]" (1928: 112). Cuando Elias habla de esta unidad biológica, no significa, sin embargo, que no reconozca la propia diversidad biológica evolutivamente adaptada a cada nicho ecológico o las diferencias genéticas heredadas, sino que es una unidad biológica radical, es decir, que no admite razas diferentes, sino simplemente contextos diversos, que son los que producen las verdaderas diferencias entre pueblos. Puesto que niega que los pueblos deban su peculiaridad a lo biológico, las causas del llamado "carácter nacional" deben ser socio-culturales" (1989: 7-8), en consonancia con los genetistas conductuales que han beneficiado a las ciencias sociales al poner cuidado en distinguir entre diferencias heredables dentro de las poblaciones y entre poblaciones.

Para Elias la "unidad de todo lo humano" ("die Einheit alles Menschlichen') hace de esta pregunta acerca de la comprensión-incomprensión "aún más difícil y aún más importante". Por supuesto, como no podía ser de otro modo en un sociólogo precavido, la comprensión o incomprensión derivará de los diversos contextos culturales en los que se insertan esas personas concretas, en tanto que la sociedad es la que activa y desarrolla de modos diversos esa unidad humana natural: "los seres humanos individuales pueden, al nacer, ser muy distintos unos de 
otros en lo referente a su constitución natural. Pero es solo en la sociedad donde el niño pequeño, con sus funciones psíquicas flexibles y relativamente indiferenciadas, se convierte en un ser diferenciado ['differenzierteres Wesen]' (1983: 40, cursiva mía).

\section{La ambigüedad eliasiana del potencial de síntesis y de autocoacción como arquitecturas innatas}

Otra cuestión clave de la naturaleza humana tiene que ver con el debate actual en psicología y neurociencias acerca de la modularidad de la mente y de la existencia o no de módulos específicos para diversas capacidades cognitivas. Algunos autores defienden una modularización masiva, otros la cuestionan. El debate acerca de qué son realmente esos módulos, si tienen correlatos neuronales concretos y de qué modo, alcanza cotas de complejidad neuropsicológicoevolutivas que no es necesario desarrollar aquí (Mundó 2006; Seok 2006; Bullinaria 2007; Kurzban y Aktipis 2007; Frankish 2011). Para introducir el papel de la naturaleza humana en las explicaciones sociales no es necesario responder de modo definitivo a esas cuestiones, pero sí afirmar la idea de que la mente no es una "tabula rasa". El cerebro, como cualquier órgano corporal y biológico, es producto de una evolución filogenética (por supuesto, es una coevolución biológico-cultural-ambiental) de al menos unos 3 millones de años, que ha debido introducir sesgos psicológicos firmemente anclados en la estructura cerebral; esta misma arquitectura posibilita la plasticidad sináptica y neuronal (que no es infinita maleabilidad, cf. Damasio 2010: 138) que permiten el gran desarrollo socio-cultural a través del aprendizaje y la cultura, y la adaptación a situaciones cambiantes. Así, en torno al $94 \%$ del volumen del cerebro es heredable. Las zonas frontal, sensoriomotora y temporal anterior están bajo control genético, y la zona frontal media, en concreto, muestra una heredabilidad estrictamente genética del 90-95 $\%$; mientras que, al contrario, las circunvoluciones o el hipocampo están más influidos por el entorno (Gazzaniga 2006: 91-92).

Por supuesto, en Elias este debate está ausente. Sin embargo, el hecho de que llevara a sus clases de sociología una maqueta del cerebro sin el cual no podría comprenderse al ser humano, no es meramente anecdótico. Elias nunca habla de "módulos" y le resultaría ajena una modularidad masiva al estilo de la psicología evolutiva. Sin embargo, es habitual en él encontrar la idea de que hay "disposiciones" o "potenciales" que pertenecen a la propia naturaleza humana, es decir, que son universales biológicos: por ejemplo, el potencial de síntesis, el potencial de coacción, la disposición a la socialidad, y las disposiciones cognitivas a la simbolización.

Respecto al primero afirma: "Los hombres poseen como parte de su dotación natural, una capacidad general de síntesis ['allgemeines Potential zur
Synthese] para relacionar hechos. Ahora bien, todos los nexos específicos que ellos establecen, así como los conceptos correspondientes que utilizan en sus discursos y reflexiones, son el resultado del aprendizaje y la experiencia" (1984: 3, cursiva mía). Para Elias el "concepto" (o el símbolo) de tiempo es un conocimiento derivado y cambiante históricamente (ahora diríamos: es un concepto cultural adaptativo), pero que encuentra su "fundamento" en una suerte de "capacidad innata de sintetizar" temporalmente los hechos, previa a la experiencia de sintetizar con tal o cual símbolo. Por ello, cuando Elias a modo de ficción imagina un punto cero en la evolución humana, un grupo humano que no tiene un saber previo recibido de otros, no puede eliminar de ellos completamente la capacidad de síntesis, aunque esté menos desarrollada: "su potencial humano de síntesis, su capacidad ['Fähigkeit'] para aprender los nexos entre acontecimientos, se realizaría casi exclusivamente para servir a [sus exigencias elementales]" (1984: 33). Es decir, ese "grupo primordial" no tendría cultura del tiempo, pero sí tendría una estructura biológica innata que le permitirá desarrollarla. Hay un sesgo psicológico innato hacia la síntesis temporal, aun cuando nada se diga sobre el tipo de calendario o de valoración del tiempo que emergerá de esa disposición. Los símbolos de medición del tiempo son culturales, pero el hecho de la propia posibilidad no es una cuestión cultural, sino estrictamente biológica; es un dato previo de la naturaleza humana.

El potencial de coacción se sitúa dentro de su proceso de civilización. Elias distingue cuatro grandes tipos de restricciones a los que se encuentran sujetas las personas (1989: 43-44): (1) Restricciones derivadas de las peculiaridades fisiológicas, como el hambre, el instinto sexual, la necesidad de cariño, amor, odio y enemistad. (2) Restricciones originadas por los eventos naturales no humanos, como la protección de las inclemencias del tiempo. (3) Restricciones que se ocasionan entre sí los seres humanos en la convivencia: son las llamadas "restricciones heterónomas", que se dan desde el momento en que incluso tan solo dos personas se hallen en relación. (4) Restricciones individuales o "autónomas", basadas en el autocontrol de la persona humana. Estas se diferencian de las primeras porque "biológicamente, lo único que tenemos es un potencial de restricción autónomo" (1989: 44). Lo esencial de esta diferenciación radica en que las restricciones del primer tipo -y con variaciones del nicho ecológico, también las del segundo- son en general las mismas para toda la especie humana, mientras que las heterónomas y las autónomas cambian con respecto a los diferentes contextos sociales e históricos. De hecho, durante el proceso de civilización lo que cambiará será la proporción entre restricciones heterónomas y autónomas (1939, II: 313). Las restricciones son de origen social, puesto que "los seres humanos no poseen restricciones innatas ['unlearned'] de sus 
fuertes afectos ni de sus impetuosos impulsos instintivos" (1986: 45), sino que lo deben aprender al contacto con la sociedad. Sin embargo, Elias insiste en que no se trata de pensar las restricciones como barreras culturales antinaturales que frenen los instintos naturales, como si la posibilidad de la coacción fuera un dato cultural exógeno a lo biológico. Si existe la posibilidad de las restricciones es porque, de hecho, hay "una disposición biológica a controlar los impulsos", es decir, un "potencial" natural para que nuestros impulsos sean contenidos (1986: 59), motivo por el que no duda en afirmar que "el aprendizaje del autocontrol es un universal humano" (ibíd.: 45). En formulación sencilla: "Las personas no son civilizadas por naturaleza, pero sí poseen por naturaleza una predisposición ('Anlage') que bajo determinadas circunstancias hace posible ('möglich macht') la civilización" (1986b: 382). Así, insiste nuestro autor: "es fácil pasar por alto que sin un potencial civilizador biológicamente dado ('biologische vorgegebenes') no serían posibles ('nicht möglich wären') los procesos de civilización" (1986b: 282). Por ello, critica que "hoy en día suele considerarse que la restricción de los impulsos es 'antinatural' ['unnatural'], contraria a la naturaleza humana. Sin embargo, ningún control posiblemente podría adquirirse ni integrarse en la estructura humana como uno de sus rasgos permanentes si en la constitución natural de los seres humanos no hubiera, como parte integral de ella, una disposición biológica ['biological disposition'] a controlar los impulsos, y si estos no poseyeran, por naturaleza propia, el potencial de ser contenidos, desviados y transformados de varias maneras" (1986: 59). Como ya insistí la coevolución biosocial permite el juego del desarrollo cultural desde una previa evolución biológica que termina siendo transformada por la primera.

Es cierto que la utilización del concepto de "potencial" y "disposición" -inunca de "módulo"!- acerca a Elias al Modelo Estándar de las ciencias sociales en el sentido propuesto por Cosmides y Tooby (1992), ya que consideran que las ciencias sociales se sienten cómodas con el concepto de "potencial" porque les facilita afirmar lo mínimo: que la biología es "mero utillaje potencial" desprovisto de cualquier sesgo de contenido concreto. De ahí que lo potencial es lo que "puede llegar a ser", pero que no "es": justamente para que sea, las ciencias sociales estándar introducen lo social, lo cultural, como elemento externo que da contenido a lo que biológicamente es mero potencial. $Y$ en torno a esta concepción ya hemos visto que gira esencialmente la visión eliasiana de la naturaleza humana. Sin embargo, aunque ambos potenciales, el de síntesis y el de coacción, quizá no puedan considerarse como "módulos" en el sentido fuerte en neurociencias y psicología evolutiva, el hecho de que considere que hay potenciales concretos para fenómenos sociales complejos tan diferentes como el tiempo, la coacción, las funciones cognitivas para simbolizar a través del lenguaje, e incluso dis- posiciones para la socialidad (cf. infra), le alejan también de una aproximación generalista de la mente humana propuesta por el constructivismo. Desde mi punto de vista, esto refuerza el hecho de que, aunque de forma precavida, Elias sigue reconociendo datos universales a la naturaleza humana, que de algún modo ya vienen modulados para tareas diferentes: sintetizar, coaccionarse, simbolizar y socializar. No se puede situar forzadamente al sociólogo alemán como un proponente de la modularidad, pero al menos sí reconocer su esfuerzo por introducir la naturaleza humana en sus explicaciones sociológicas.

\section{La natural complejidad de la socialidad humana}

De todo lo anterior se deriva que para Elias el ser humano tiene una dependencia radical, ontológica, de otros seres humanos para poder activar sus potenciales biológicos innatos y para configurar de modo concreto el "vector" exterior, dando lugar a un "troquelado sociogenético" ('soziogene Ausprägung') (1983: 59). La importancia de este proceso doble de "troquelado" de la sociedad sobre disposiciones naturales innatas es lo que permite la posterior influencia de lo social sobre lo natural, en un proceso dialéctico en el que lo natural-innato posibilita su determinación social, y a su vez esta determinación social tiene influencia sobre lo natural-innato, sin lugar, pues, para consideraciones dualistas, como bien se refleja en su proceso de civilización (Quilley 2010: 414).

La naturaleza humana es radicalmente referencia a los otros. De hecho, la antropología eliasiana tiene como uno de sus rasgos básicos y mejor conocidos su crítica del homo clausus y su popularización de lo que él denomina homines aperti, que no deja de ser la explicitación o fundamentación antropológica de las figuraciones e interdependencias. También aquí existe un claro anclaje biológico de su antropología. Lo que Elias denomina el "vector" ('Vektor') hacia los demás y hacia las cosas pertenece a la propia estructura natural del ser humano, lo que supone que "el ser humano por naturaleza está organizado como parte de un universo mayor" (1983: 58), aunque "las disposiciones innatas a la vida con los demás requieren ser activadas mediante el aprendizaje" (1985: 11). La consideración del "Vektor" de raigambre biológica, que es una suerte de instinto -pero no preprogramación-, hacia la relación con los otros, podría hacer de la sociología eliasiana un interlocutor fértil con algunas corrientes que ponen de manifiesto la complejidad biopsicosocial de la socialidad humana.

Así, por ejemplo, con la postura de Turner y Maryanski (Maryanski 2013; Turner 2013; Turner y Maryanski 2013), quienes vienen insistiendo en que los seres humanos somos más semejantes a los solitarios simios (ape) que a los gregarios monos (monkey), debido a que carecemos de bioprogramadores que naturalmente nos faciliten la construcción de vínculos sociales. Estos vínculos sociales, 
esenciales para la vida humana, se producen trabajosamente, comenzando siempre en la copresencia física a través de capacidades neurológicas (que han emergido evolutivamente) que permiten a las personas presentar ellas mismas y recibir de las otras señales facilitando la asunción mutua de roles, emociones, culturas, estatus, atribuciones, etc., que generan dinámicas emocionales compartidas, en el sentido desarrollado por Collins (2004, cf. Romero 2013c), dando lugar a una gran complejidad afectiva (Iranzo 2013: 119). De esos vínculos primeros se abrirá la posibilidad de generar relaciones que puedan mantenerse a distancia por procedimientos formalizadores impersonales: son los llamados "vínculos débiles", que exigen capacidades cognitivas evolutivas más complejas.

En el mismo sentido, Dunbar estableció su tesis del "cerebro social" y su famoso "número Dunbar" que limita aproximadamente a 150 el número de personas que el cerebro humano (más concretamente establece una relación entre el neocórtex de diversas especies y el tamaño de sus grupos sociales) puede tener capacidad para establecer relaciones íntimas y coherentes. La cuestión es que, aunque nuestra socialidad no está preprogramada, el ser humano posee unas habilidades cognitivas que le permiten gestionar las complejidades de las relaciones sociales: tener una teoría de la mente exige un conocimiento e intimidad de las personas, que no puede ser superior a ese número, pero también posibilita tener relaciones sociales con personas que no están presentes, lo que permite amplificar el mundo social de los humanos (Dunbar 2010; Gamble et al. 2014). En este sentido, si para Turner y Maryanski la biología pone una limitación a la fácil socialidad humana por carencia de bioprogramadores, para Dunbar la limitación biológica viene dada por la constricción del neocórtex y su capacidad para establecer relaciones íntimas más allá de un número determinado. El neocórtex es un dato biológico previo que, por así decirlo, constriñe las posibilidades de desarrollo cultural, aunque con el tiempo este último pueda, a su vez, amplificar el primero.

También Richerson y Boyd (2005) introducen una paradoja biológica en la socialidad humana, al establecer dos tipos de "instintos sociales" (el de parentesco y el tribal), que han emergido coevolutivamente y que son contradictorios entre sí: los instintos de parentesco favorecen comportamientos cooperativos con nuestros parientes y allegados, en tanto que el instinto tribal (seguramente único a la especie humana) favorece la cooperación y el altruismo en grandes grupos y organizaciones de personas no emparentadas entre sí (por encima, pues, del número de Dunbar). Las lealtades ambivalentes hacia uno $\mathrm{u}$ otro grupo emergen continuamente, haciendo de la vida social fuente continúa de conflictos que están inscritos en nuestra propia biología ambivalente (Romero Moñivas 2016).
De esta forma, la naturaleza humana se corresponde con una compleja socialidad que no puede desembarazarse fácilmente de lo biológico. En consonancia con ello Elias ha insistido, frente al funcionalismo parsoniano, en que la figura concreta de las figuraciones sociales deriva de los desequilibrios cambiantes de poder, y que las figuraciones son siempre armónico-conflictivas a un tiempo (1969b: 215, 1970: 142). Sus modelos de juegos (1970: 78ss) reflejan esa complejidad biológica de la socialidad humana. Ser humano es un trabajo socialmente duro, que requiere una arquitectura cerebral innata para desarrollar relaciones sociales complejas, más allá de los vínculos fuertes de parentesco: pero esta arquitectura innata no es un "programa genético" de gregarismo social como en el caso de los insectos $\mathrm{y}$, en menor medida, los monos (por oposición a los homínidos). Al contrario, los seres humanos (y seguramente toda la línea homínida), evolutivamente más semejantes a los grandes simios, tienen que establecer relaciones sociales basadas en mecanismos complejos de teoría de la mente, de lectura de señales emocionales y simbólicas, a través de la incertidumbre, de lealtades contrapuestas, de instintos sociales ambivalentes entre el parentesco y las grandes agrupaciones, que requieren arquitecturas cerebrales concretas (Shook 2013; Turner 2013b; Hopcroft 2013). Algo semejante al Ilamado por Elias "mecanismo real" (1969b: 107-110), que permitía a Luis XIV gestionar las complejas figuraciones sociales de la sociedad cortesana.

Por lo tanto, en esta referencialidad a los otros hay una herencia biológica y una herencia sociológica, un Vektor genético que se concretiza en las relaciones sociales del sujeto. Cuando Elias habla de la herencia sociológica no está reduciendo este proceso de "socialización" a la estructura familiar. La conformación antropológica del ser humano no es, para Elias, una función de un grupúsculo nuclear al que llamamos familia (1965). Esa visión estrecha de los vínculos familiares es empíricamente insostenible, por cuanto falsea el proceso de crecimiento y desarrollo humano, como si el niño fuera únicamente conformado por una "entidad familiar autosuficiente", sin tener en cuenta que la propia unidad familiar no puede escapar a los vínculos suprafamiliares que conforman las comunidades más amplias. En este sentido, la radical dependencia del ser humano de los "otros" trasciende los estrechos márgenes de la familia. Aunque la sociología ha destacado siempre la influencia de los "pares" y de las "socializaciones secundarias", sigue jugando con la idea básica de que es la familia, la socialización primaria en los tres primeros años de vida, la que determina en gran medida la identidad del sujeto individual. Elias parece alejarse de ese supuesto, lo que le permitiría un diálogo más abierto con las investigaciones de la genética conductual (y sus tres leyes de la herencia), que insisten en que la identidad a largo plazo de los suje- 
tos no viene influida apenas por la educación de los padres sino por los grupos de pares y las idiosincrasias propias de cada vida individual. Así, la variación de los rasgos conductuales humanos (la "heredabilidad") viene dada en una proporción de 40-50 \% los genes, $0-10 \%$ el medio compartido y $50 \%$ el medio exclusivo (Pinker 2002).

En esta misma línea, pero en el enfoque coevolutivo, como insistí más arriba, también se ha puesto de manifiesto que precisamente el carácter no adaptativo de muchos de los elementos del desarrollo cultural vienen determinados por su aprendizaje fuera del núcleo parental (imitando comportamientos comunes, de personas exitosas, etc.), reduciendo así la selección natural de rasgos biológicos adaptativos. Esto supone que el ser humano recibe su carácter individual "de la historia de sus relaciones, sus dependencias y necesidades, y, en un contexto mayor, de la historia de todo el tejido humano en el que crece y vive" (Elias 1983: 48). De hecho, esta cuestión es clave para comprender lo que Elias Ilama la estructura social de la personalidad (1989: 35); su psiquismo es producto del troquelado social, no solo del presente, sino de todo el proceso histórico y filogenético que desemboca en él: "Solo mediante un largo y arduo cincelado ['Ausziselierung'] de sus maleables funciones psíquicas, realizado en el trato con otras personas, adquiere la dirección de los comportamientos de un ser humano aquella cualidad constitutiva única que caracteriza a una individualidad humana específica" (1983: 90). El ser humano en Elias se construye en base a interdependencias que trascienden la interacción, y por tanto son por definición abiertas y no estáticas ni esencialistas (1983: 48). Solo una arquitectura cerebral evolutivamente gestada en procesos coevolutivos genes-cultura, podría dar lugar a tal extraordinaria capacidad de socialidad compleja, aunque la insistencia de Elias en la "maleabilidad" de esa arquitectura le impida profundizar más en los actuales hallazgos de la neurociencia.

\section{LA IMPORTANCIA DE LA DIMENSIÓN PROCESUAL-EVOLUTIVA}

Al contrario que una gran parte de la sociología moderna -a la que acusó de retraimiento en el presente (1987b) - , a menudo indiferente a la dinámica evolutiva y al desarrollo histórico, para Elias la dimensión procesual, dinámica e histórica es ineludible. La suya no es una simple sociología histórica, sino incluso "macro-evolutiva", que trata de integrar la evolución cósmica, con la evolución biológica y el desarrollo cultural. La procesualidad y el dinamismo de la realidad son dimensiones que han acompañado a Elias desde su juventud y que se rastrean ya en su Vom Sehen in der Natur escrito con 24 años. Por ello se opone fuertemente al estatismo, al que considera producto de la filosofía occidental y de su obsesiva búsqueda de lo inmutable, de lo eterno, de la quietud, como valor ontológico superior a lo dinámico, al cambio y al proceso (1982: 12). Es decir, de la concepción de "lo invariable como lo auténtico y lo esencial en todos los fenómenos" (1970: 120). Según Elias "salvo algunas excepciones -Hegel, Comte-, los filósofos caen siempre en la tentación de reducir, como accidentales, los procesos observables a algo inmutable y absoluto. [...]" (1984: 106). Esto es lo que Elias ha denominado la tendencia en el pensamiento occidental a la "reducción de procesos" ('Zustansreduktion') que tiene en la "ley" su pivote epistemológico. Esta reducción de los procesos viene reforzada por nuestros lenguajes que hacen difícil la expresión del movimiento (1970: 119); y no está únicamente presente en la filosofía, sino que en la propia sociología "el cambio social [...] aparece como una manifestación de perturbación casual”, es decir, "una transición entre dos situaciones normales de inmutabilidad" (1939, I: p. 20). Por ello, para cambiar nuestras concepciones estáticas es necesario cambiar nuestros conceptos y lenguajes con los que pensamos la realidad. Elias critica que el descubrimiento de algo eternamente inmutable tras todos los cambios temporales se haya convertido en el "máximo galardón de la búsqueda humana del conocimiento; [que] derivaba de la nostalgia ['der Sehnsucht'] de algo duradero tras el cambio incesante de todos los datos observables y la búsqueda de algo imperecedero y atemporal tras su vida transitoria" (1984: 107), como un "mito" que calma la inquietud humana. El dinamismo de la realidad es tan ontológicamente radical, que se extiende hacia el pasado y el futuro, en un sin fin de procesos que no tiene un punto de inicio ni conclusión. De hecho, en sus escritos juveniles utilizaba con profusión el término "infinito" e "infinitud" para describir este dinamismo sin fin, este "proceso infinito" ('unendlichen Prozeß') (1921: 23-24 y 28). Incluso, en oposición a los modelos estándar de cosmología y de partículas (Narlikar y Padmanabhan 2001; Yndurain 2006), Elias aceptará de mala gana el Big Bang como punto de partida de su proceso de evolución de niveles de integración, porque para él no dejaba de ser un "mito físico" para calmar la ansiedad humana anhelante de un principio absoluto; incluso le parecía "bastante dudosa" la idea de una última 'partícula primordial' (1983b: 188). Este dinamismo de la realidad cosmológico-natural tiene consecuencias antropológicas y sociológicas, puesto que impregna aquellos otros niveles de integración posteriores, como la sociedad y el ser humano: dirá, de hecho, que el individuo es "un hombre que cambia, que no solo, como se expresa en ocasiones, atraviesa ['durchläuft'] un proceso [...]; él mismo es un proceso" (1970: 127). Si la realidad cósmica es cambiante y procesual, así también lo será el ser humano y las figuraciones e interdependencias que se constituyen históricamente. Este dinamismo de calado ontológico es vital para aceptar la importancia del papel de la naturaleza físico-biológica, ya 
que exige la perspectiva evolutiva como condición explícita para comprender la arquitectura cerebral y biológica del ser humano.

\section{LA RELACIÓN EPISTEMOLÓGICA ENTRE LA SOCIOLOGÍA Y LAS CIENCIAS FÍSICO-NATURALES}

Finalmente, también transversal es el problema de la relación entre las diferentes ciencias. Como gran parte de los científicos sociales de tendencia más naturalista (Wilson 1998; Keestra 2011), Elias aboga por una verdadera interdisciplinariedad. Cierto es que para que existan "ciencias" diferentes, debe de haber "objetos de estudio" diferentes, pero esta autonomía de cada objeto de estudio es solo relativa. Los diversos ámbitos que emergen de la Gran Evolución sufren entre sí una tensión dialéctica entre su carácter emergentista y su autonomía no reductible. Y si existe el peligro de reducir la biología a la física, también existe el de reducir lo social a lo biológico. Por ello, insiste en que "las ciencias físicas, las biológicas y las sociológicas se ocupan de diferentes planos de integración del universo" (1970: 47). Ahora bien, tan ilegítima es la reducción de lo social a lo biológico proclive en algunos biólogos, como el hecho de que los sociólogos "ha[yan] desarrollado una especie de repulsión traumática a todo intento de dilucidar las relaciones entre aquellos niveles de integración precedentes, sobre todo con el biológico" (1983b: 235). Esta "postura defensiva" de los sociólogos frente a biólogos y físicos olvida que "también los seres humanos están compuestos de átomos y moléculas. [...] de células. [...] de tejidos, de órganos y de sistemas de órganos [...]" (1983b: 236), lo que les conduce a hablar "a menudo acerca de la sociedad sin vincularla a los aspectos biológicos de las personas" (1984b: 40). Elias, al contrario, opina que "no se puede, por ejemplo, proponer ninguna teoría de la actividad humana si no se sabe cómo está constituido el organismo y cómo actúa. Incluso [...] se proyectan teorías sobre el conocimiento con total ignorancia de las estructuras del cerebro" (1984b: 41). Como es bien sabido, Elias estudió medicina en Breslau hasta la etapa clínica (el Physikum), para luego abandonarla y concentrarse en la filosofía. En muchas ocasiones ha puesto de manifiesto esos estudios como influencia de su imagen más realista del hombre y de su gusto por la interdisciplinariedad. Quizá también expliquen el hecho de que "en ocasiones, yo mismo llevaba a mis clases [hasta la década de 1960] de sociología una maqueta del cerebro para mostrar a los estudiantes cómo está estructurado el hombre, pues solo entonces pueden comprender el funcionamiento de las sociedades. De ese modo no reduzco la sociología a la biología". (1984b: 41, cursiva mía). Incluso, afirmó que la psicología era el puente entre las ciencias de la naturaleza y las ciencias sociales (1983: 64-65). La sociología tal como la concibe Elias es una ciencia que "descubre" -se aleja en este punto explícitamente de Mannheim del que afirma que para él "todo es ideológico" (1984b: 84)-, que libera las teorías sociales de los "mitos" creando conceptos "más congruentes con la realidad" y lo hace solo con "relativa autonomía" de las ciencias físico-naturales, de las que siempre necesita un conocimiento actualizado para lograr una imagen sociológica más real del ser humano. La ciencia y el conocimiento del mundo es posible porque el ser humano no es lo "otro" de la realidad físico-natural, no es un "yo" ni una "conciencia" ni una "mente espiritual" encerrada en sí misma (1983: 154-155). Al contrario, las personas son "individuos coordinados desde sus fundamentos con un mundo, con aquello que no es él, con otras cosas y, en especial, con otros seres humanos" (1984b: 150). El sujeto cognoscente es un ser humano ya integrado en la propia macro-evolución de la naturaleza físico-biológica, de ahí que sus capacidades cognitivas no se hayan desarrollado meramente en interacciones sociales como una capacidad espiritual, sino que han emergido de una evolución filogenética en contacto con el mundo natural y social. No podría ser de otro modo en una gnoseología como la elisiana que deriva de una previa ontología emergentista, pero monista.

\section{Conclusiones}

A lo largo de estas páginas he intentado desarrollar algunos de los puntos esenciales de la obra eliasiana que tienen relación con el papel de la naturaleza físico-cosmológica y de la naturaleza biológica. Por supuesto, en Elias estas consideraciones no son un puro divertimento intelectual, sino que están en la base de su comprensión sociológica y antropológica. A modo de recapitulación, trataré de enumerar los rasgos más importantes: (a) su ontología monista emergentista tiene consecuencias importantes porque de ahí derivarán aspectos como su rechazo del dualismo y su ontología social figuracional. (b) Elias utiliza con cierta asiduidad el concepto -cuasi tabú en sociología- de "naturaleza humana". Sin embargo, su uso bascula entre el naturalismo y el sociologismo, más cerca del segundo que del primero, aunque con una clara apuesta por la inclusión de lo biológico en su sociología. Respecto a la naturaleza humana en Elias puede decirse que siempre está presente de un modo u otro como la base posibilitadora de fenómenos sociales más complejos, como por ejemplo, la capacidad de sintetizar hechos, la posibilidad de un proceso de civilización a través de restricciones de los afectos, la ejercitación simbólica y la apertura hacia una socialidad compleja. Muchas de sus explicaciones muestran una explícita (y no meramente implícita) comprensión coevolutiva entre lo biológico y lo cultural, lo que resulta en un proceso complejo en el que lo biológico como potencial permite fenómenos sociales que luego, de hecho, pueden contravenir la origina- 
ria naturaleza humana, en una dialéctica influencia biosocial entre la evolución biológica y el desarrollo histórico-cultural. Aunque Elias de ningún modo habla de la mente humana ni del cerebro como un arquitectura modular de contenido concreto, sí que podemos decir que tampoco parece defender una mente generalista y absolutamente indiferenciada al estilo constructivista-sociologista. (c) La importancia que le da al dinamismo ontológico de la realidad ha facilitado que a menudo en sus obras sociológicas trate cuestiones evolutivas, macro-cosmológicas y filogenéticas. (d) Finalmente, la propia posibilidad de que exista una ciencia que "descubre" y no meramente "construye" su objeto de estudio se debe a que las capacidades cognitivas del ser humano no han surgido simplemente de interacciones sociales, sino al contacto con el mundo natural de los objetos. De ahí que su epistemología considere que las ciencias tienen solo relativa autonomía unas de otras, ya que cada una se ocupa de un nivel emergente que solo tiene relativa autonomía del precedente. Con todo esto no pretendo afirmar ni que la sociología de Elias "sea" naturalista, ni que el propio Elias "lo pretendiera". En términos generales la producción eliasiana está muy alejada de los trabajos que consideramos encuadrados plenamente en este enfoque. Pero al sociólogo alemán no se le puede obviar el mérito de haberse interesado por las ciencias físico-naturales y de haber tratado -con más o menos éxito y consistencia- de integrar lo cultural y lo biológico, una necesidad que aun en nuestros días sigue siendo una excepción en la sociología.

\section{NOtAS}

El "emergentismo" es una teoría compleja con multitud de derivaciones y debates abiertos. Sería interesante desarrollar el emergentismo eliasiano en discusión con las diversas alternativas. Sin embargo, no es el objetivo de este epígrafe en el que considero que basta una definición general (como opuesta al fisicalismo y al dualismo) para atribuírsela a Elias.

\section{RefERENCIAS BibLIOGRÁficas}

Bullinaria, J. A. 2007. "Understanding the Emergence of Modularity in Neural Systems", Cognitive Science 31: 673695. http://dx.doi.org/10.1080/15326900701399939

Castro Nogueira, M. Á., L. Castro Nogueira y L. Castro Nogueira. 2008. ¿Quién teme la naturaleza humana? Homo suadens y el bienestar en la cultura: biología evolutiva, metafísica y ciencias sociales. Madrid: Tecnos.

Castro Nogueira, L. 2013. "Contra el sociologismo: observaciones naturalistas a propósito de un ensayo de Juan Manuel Iranzo". Revista Española de Sociología 22: 101-114.

Churchland, P. M. 1981. "Eliminative Materialism and the Propositional Attitudes". Journal of Philosophy 78: 6790. http://dx.doi.org/10.5840/jphil198178268

Churchland, P. S. 2012. El cerebro moral. Lo que la neurociencia nos cuenta sobre la moralidad. Barcelona: Paidós.

Churchland, P. S. 1986. Neurophilosophy: Toward a Unified Science of the Mind/Brain. Cambridge, MA: MIT Press.

Collins, R. 2004. Interaction Ritual Chains. Princeton: Princeton University Press. http://dx.doi. org/10.1515/9781400851744

Damasio, A. 2010. Self Comes to Mind. Constructing the Conscious Brain. New York: Pantheon Books.

Dunbar, R. 2010. How Many Friends Does One Person Need? Dunbar's Number and other evolutionary quirks. London: Faber and Faber.

Dunbar, R., L. Barret y J. Lycett. 2011. Evolutionary Psychology. Human behaviour, evolution and the mind. Oxford: Oneworld.

Dunning, E. 1986. "Preface”. Pp. 1-18 en Quest for Excitement: Sport and Leisure in the Civilizing Process, editado por N. Elias y E. Dunning. Oxford: Basil Blackwell.
Elias, N. [1921] 2002. Vom Sehen in der Natur. Band I, Frühschriften. Pp. 9-28 en Gesammelte Schriften, editado por Reinhard Blomert. Frankfurt a.M.: Suhrkamp.

Elias, N. [1939] 1981-1982. Über den Proze $\beta$ der Zivilisation. Soziogenetische und psychogenetische Untersuchungen. Basel (Haus zum Falken): Suhrkamp.

Elias, N. 1956. "Problems of involvement and detachment". British Journal of Sociology 7: 226-252.

Elias, N. y John L. Scotson. 1965. The Established and the Outsiders: A Sociological Enquiry into Community Problems. London: Sage 1994.

Elias, N. 1969. "Sociology and psychiatry". Pp 117-144 en Psychiatry in a Changing Society, editado por S. H. Foulkes y G. Stewart Prince. London: Tavistock.

Elias, N. 1969b. Die höfische Gesellschaft: Untersuchungen zur Soziologie des Königstums und der höfischen Aristokratie, mit einer Einleitung: Soziologie und $\mathrm{Ge}$ schichtswissenschaft. Neuwied/Berlin: Luchterhand.

Elias, N. 1970. Was ist Soziologie? München: Juventa Verlag.

Elias, N. 1970b. "African Art". Pp. 132-140 en The Norbert Elias Reader: A Biographical Selection, editado por Johan Goudsblom y Stephen Mennell. Oxford: Blackwell.

Elias, N. 1971. "Sociology of Knowledge: New Perspectives". Sociology 5: 149-168; 355-370.

Elias, N. [1974] 1998. "The Sciences: Towards a Theory". Pp. 152-165 en The Norbert Elias Reader: A Biographical Selection, editado por Johan Goudsblom and Stephen Mennell. Oxford: Blackwell. (Reimpresión incompleta, pero suficiente en lo esencial).

Elias, N. 1974. "Towards a Theory of Communities". Pp. ix- xli en The Sociology of Community: A Selection of Readings, editado por Colin Bell y Howard Newby. London: Frank Cass. 
Elias, N. 1980. "Civilización y violencia", Revista Española de Investigaciones Sociológicas 65: 141-151.

Elias, N. 1982. "Scientific Establishments". Pp. 3-70 en Scientific Establishments and Hierarchies, editado por Norbert Elias, Herminio Martins y Richard Whitley. Dordrecht: Reidel.

Elias, N. 1983. Die Gesellschaft der Individuen. Frankfurt am Main: Surhkamp.

Elias, N. 1983b. Engagement und Distanzierung. Arbeiten zur Wissenssoziologie I. Frankfurt am Main: Suhrkamp.

Elias, N. 1984a. Über die Zeit: Arbeiten zur Wissenssoziologie II. Frankfurt am Main: Suhrkamp.

Elias, N. 1984b. Mi trayectoria intelectual. Barcelona: Península 1990.

Elias, N. 1985. La soledad de los moribundos. México: Fondo de Cultura Económica.

Elias, N. y Eric Dunning. 1986. Quest for Excitement: Sport and Leisure in the Civilizing Process. Oxford: Basil Blackwell.

Elias, N. 1986b. "Zivilisation”. Pp. 382-387 en Grundbegriffe der Soziologie, editado por Bernhard Schäfers. Opladen: Leske \& Budrich.

Elias, N. 1987. "On Human Beings and Their Emotions: A Process-Sociological Essay". Pp. 103-25 en The Body: Social Process and Cultural Theory, editado por Mike Featherstone, Mike Hepworth y Bryan S. Turner. London: Sage.

Elias, N. 1987b. "The Retreat of Sociologists into the Present". Theory, Culture and Society 4: 223-49. http://dx.doi. org/10.1177/026327687004002003

Elias, N. 1989. Los alemanes. México: Instituto Mora.

Elias, N. 1991. The Symbol Theory. London: Sage.

Elias, N. 1991b. Mozart: Sociología de un genio. Barcelona: Península.

Flint, J., R. J. Greenspan y K. S. Kendler. 2010. How genes influence Behavior. Oxford: OUP.

Frankish, K. 2011. "Cognitive Capacities, Mental Modules, and Neural Regions". Philosophy, Psychiatry and Psychology 4: 279-282. http://dx.doi.org/10.1353/ppp.2011.0052

Gamble, C., J. Gowlett y R. Dunbar. Thinking Big. How the Evolution of Social Life Shaped the Human Mind. London: Thames and Hudson.

Gazzaniga, M. S. 2006. El cerebro ético. Barcelona: Paidós.

Greenspan, R. J. 2004. "E pluribus unum, ex uno plura: Quantitative- and single-gene perspectives on the study of behaviour". Annual Review of Neuroscience 27: 79-105. http://dx.doi.org/10.1146/annurev.neuro.27.070203.144323

Iranzo, J. M. 2013. "Naturaleza y sociedad. Respuesta Luis Castro". Revista Española de Sociología 22: 115-122.

Keestra, M. 2011. "Understanding Human Action: Integrating Meanings, Mechanisms, Causes, and Contexts". Pp. 225-258 en Interdisciplinary Research: Case Studies of Integrative Understandings of Complex Problems, editado por R. Allen, S. Rick y N. William. New York: Sage.

Kilminster, R. 2007. Norbert Elias: Post-philosophical Sociology. London: Routledge.

Kurzban, R. y C. A. Aktipis. 2007. "Modularity and the Social Mind: Are Psychologists Too Self-Ish?". Personality and Social Psychology Review 11: 131-149. http:// dx.doi.org/10.1177/1088868306294906

Llinas, R. 2003. El cerebro y el mito del yo. Barcelona: Belacqua.

Mayr, E. 1982. The Growth of Biological Thought. Cambridge: Harvard University Press.
Maryanski, A. 2013. "Secret of the Hominin Mind: An Evolutionary Story". Pp. 257-287 en Handbook of Neurosociology, editado por David Franks y Jonathan Turner. New York: Springer.

Mundó, J. 2006. "Filosofía, ciencia social y cognición humana: de la folk psychology a la psicología evolucionaria". Papers 80: 257-281.

Narlikar, J. V y T. Padmanabhan. 2001. "Standard Cosmology and Alternatives: A Critical Appraisal”. Annual Review of Astronomy and Astrophysics 39: 211-248. http:// dx.doi.org/10.1146/annurev.astro.39.1.211

Outhwaite, W. 2006. The Future of Society. Oxford: Blacwell Publishing. http://dx.doi.org/10.1002/9780470773505

Pinker, S. 2002. La tabla rasa. La negación moderna de la naturaleza humana. Barcelona: Paidós.

Quilley, S. 2010. "Integrative levels and 'the Great Evolution': Organicist biology and the sociology of Norbert Elias". Journal of Classical Sociology 10: 391-419. http:/l dx.doi.org/10.1177/1468795X10385179

Romero Moñivas, J. 2016. "Una aproximación teórica a la ambivalencia humana y sus implicaciones para la sociología". Empiria 33: 37-64.

Romero Moñivas, J. 2013a. "El problema de la libertad en Norbert Elias en diálogo con las neurociencias". Revista Española de Investigaciones Sociológicas 142: 93-116.

Romero Moñivas, J. 2013b. Los fundamentos de la sociología de Norbert Elias, Valencia: Tirant lo Blanch.

Romero Moñivas, J. 2013c. "Unificando macro y micro. Una aproximación global a la sociología de Randall Collins". Revista Española de Sociología 20: 63-103.

Richerson, P. J. y R. Boyd. 2005. Not by genes alone. How culture transformed human evolution. Chicago: The Chicago University Press.

Sanguineti, J. J. 2014. Neurociencia y filosofía del hombre. Madrid: Palabra

Seok, B. 2006. "Diversity and Unity of Modularity". Cognitive Science 30: 347-380. http://dx.doi.org/10.1207/ s15516709cog0000_52

Soler, M. 2002. “¿A qué nivel actúa la selección natural?”. Pp. 75-82 en Evolución. La base de la biología, editado por M. Soler. Granada: Proyecto Sur de Ediciones.

Tooby, J. y L. Cosmides. 1992. "The Psychological Foundations of Culture". Pp. 19-136, en The Adapted Mind. Evolutionary Psychology and the Generation of Culture, editado por J. H. Barkow, L. Comides y J. Tooby. New York: Oxford University Press.

Turner, J. 2013. "Neurology and Interpersonal Behavior: The Basic Challenge for Neurosociology". Pp. 119-137 en Handbook of Neurosociology, editado por David Franks y Jonathan Turner. New York: Springer. http:// dx.doi.org/10.1007/978-94-007-4473-8_10

Turner, J. y A. Maryanski. 2013. "The Evolution of the Neurological Basis of Human Sociality". Pp. 289-309 en Handbook of Neurosociology, editado por David Franks y Jonathan Turner. New York: Springer. http:// dx.doi.org/10.1007/978-94-007-4473-8_19

Wilson, E. O. 1998. Consilience: The Unity of Knowledge. New York: Vintage Books.

Wilson, D. S. y E. O. Wilson. 2009. "Evolución por el bien del grupo". Investigación y ciencia (Enero): 46-57.

Wilterdink, N. 2012. "Controversial science: good and bad sociology". Figurations 36: 1-12.

Yndurain, F. J. 2006. Electrones, neutrinos y quarks. La física de particular en el siglo XXI. Barcelona: Drakontos. 
JESÚS ROMERO MOÑIVAS es profesor de Sociología en la Universidad Complutense de Madrid (Sección Departamental Sociología VI) y profesor-tutor de Ciencia Política e Historia en la UNED (Madrid-Sur). Fundador de la Asociación Interdisciplinar de Investigación Científica e Intervención Social-UBUNTU. Entre sus últimas publicaciones pueden destacarse: Los fundamentos de la sociología de Norbert Elias (Tirant lo Blanch, 2013), "El problema de la libertad en Elias en diálogo con las neurociencias" (en REIS 2013), "Una aproximación teórica a la ambivalencia humana y sus implicaciones para la sociología", (en Empiria 2016), "Unificando micro y macro. Una aproximación global a la sociología de Randall Collins" (en RES 2013), y "The Margins of Free Action. Toward a Situational Understanding of the Human Being" (en International Journal of Contemporary Sociology 2014). (acceso a varias publicaciones: jesromero.wordpress.com). 